\title{
Emerging Issues in the Nigerian 9-Year Basic Education Curriculum: Implications for Cultural and Creative Arts Education
}

\author{
Ebele V. Ojukwu \\ http://dx.doi./org/10.4314/ujah.v20i2.4
}

\section{Abstract}

This qualitative research study sought to assess and evaluate the emerging issues in the teaching and learning of cultural and creative arts (CCA) in Anambra state of Nigeria. Data was gathered through oral consultations while the historical background of the cultural and creative arts in Nigeria is employed as the theoretical frame work upon which the study is based. The paper argues that for school curriculum reforms to meet the needs of the basic education system, the school-based practices should be made to respond to school curriculum reforms. The paper concludes by suggesting that progress can only be made in CCA education if there are serious reforms in pedagogical content at the level of pre-service teacher education as well as capacity building workshops for serving teachers.

Keywords: 9-Year basic education curriculum, Cultural and creative arts education, Emerging issues, and Teachers reflections

\section{Introduction}

The adoption of the 9-Year basic education curriculum which incorporated the single-subject curriculum and the compoundsubject curriculum caused some controversy. The major challenge has been how to deal with the compound-subject curriculum where a specialist in a single-subject is made to teach a compound-subject 
of which the cultural and creative arts (CCA) is one. The cultural and creative arts education has been in existence in the Nigerian school curriculum for the past fourteen years beginning from 2004. Its adoption has been met with criticisms from various scholars. Some argued that the emergence of the three arts subjects (music, fine and applied arts and drama/theatre) is a misnomer at the time. Some challenged the distribution of the course contents and asked why some of the courses were favoured while others were marginalized. Some vehemently called for disintegration of the merged subjects and demanded that the subjects be allowed to stay on their own. Some others argued that the teachers who are specialists in different subject areas should not be made to teach other subjects outside their area of specialization. Despite all these criticisms, the Nigerian government did not bulge but rather persisted on the merger. Since 2004, when the Nigerian government adopted a free, compulsory and continuous 9-year Universal Basic Education program (UBE) in order to meet the ideals of Millennium Development Goals (MDGS), the program has been restructured severally in order to meet up with various challenges confronting it.

The inception of the new cultural and creative arts curriculum in 2004 also coincided with the restructuring of the existing primary and junior secondary school curricula with the inclusion of new subject matters in science, technology, mathematics, national values, Information and Communication Technology (ICT), vocational studies, entrepreneurship (Obioma, 2012). According to Obioma:

Basic Education Curriculum (BEC) was implemented systematically in year one of the primary and junior secondary schools respectively beginning from September 2008. After three years of the first cycle of implementation, 
BEC has been further reviewed to reduce the overload while incorporating emerging issues and maintaining quality. The revised BEC is planned to take off in year one of the primary and junior secondary schools beginning from September 2012 while the old BEC will be systematically phased out (p. 1).

Nwachukwu, (2012) gave some insight into the reason for the latest revision of the Basic Education curriculum as a result of the feedback from the implementation of the 9-year basic education curriculum, and the 2010 presidential summit on the state of education in Nigeria. This resulted in the reduction of number of subjects offered in the basic education level leading to merging of more subjects bringing the total number of subjects offered in the upper basic level to ten (10) as Nwachukwu posits "NERDC has revised and restructured the 9-Year BEC into 10 teachable, functional and practical oriented subjects that eliminated redundancy; without compromising the quality of education received by the learner" (p. 3). This is opposed to between 12-15 subjects offered previously in the basic education curriculum. The above mentioned restructuring and readjustment were carried out due to pressure, complaints and petitions from various groups including Association of Nigerian Musicologists (ANIM), Conference of Music Educators in Nigeria (COMEN), National Teachers Institute (NTI), etc. Many years have elapsed since the last readjustment and the first group of JSS 1 that started the programme has sat for the Basic Education Certificate Examination (BECE). This study attempted to scrutinize the programme especially with regards to the music aspect of CCA in order to find out the extent the ideals of Millennium Development Goals (MDGS) have been met and the emerging issues in the 
teachers' involvement in the programme. This informed the investigation into the new curriculum in order to find out the emerging issues in the system and the teachers' perception of it.

The area of the study is Awka in Anambra State. The targeted population of the study is CCA teachers presently teaching in the upper basic classes. The accessible population is CCA teachers in Awka educational zones. The sample of the study stood at Eight (8) CCA teachers drawn from five different schools in Awka educational zone. The instrument for the study is oral interview of the teachers. Simple percentage was employed for data analysis.

\section{Conceptualization of Some Basic Keywords}

\section{9-Year Basic Education Curriculum}

The Nigerian educational system has witnessed tremendous growth and expansion since independence in 1960. At the advent of the democratic government in 1999, President Obasanjo's administration in May, 1999 made education one of its priorities by introducing Universal Basic Education (UBE). The UBE scheme was put in place to improve on the limitations of Universal Primary Education (UPE) of the 1970s. With the introduction of UBE, the system of 6-3-3-4 was initiated followed shortly by the 9-3-4 system which is the latest Nigerian educational initiative. Based on UBE framework, Nigeria adopted a free, compulsory and continuous 9-year Universal Basic Education programme (UBE) in 2004. This was as a result of the Federal government strategy known as the National Economic Empowerment and Development Strategy (NEEDS). This strategy has prompted among other things in Nigeria, the following: 
- Adoption of the compulsory 9-year Basic Education programme;

- Adoption of a new curriculum structure (lower basic, middle basic and upper basic) for the implementation of the 9-year basic and the senior secondary education programmes; and

- Restructuring the existing subject profile for primary, junior secondary and senior secondary schools, respectively (Nwachukwu, 2012).

Following the introduction of the 9-year basic and compulsory education, the Nigerian Educational Research and Development Council (NERDC) developed and published new curriculum as approved by the National Council on Education (NCE) with effect from September 2007 (Ojukwu, 2011). The new curriculum was designed to fill the gaps in the old curriculum, introduce new subjects to replace obsolete subjects, redefine core subjects and also meet the key targets of the National Economic Empowerment and Development Strategy (NEEDS). These key targets are expressed as: value re-orientation; poverty eradication; job creation; wealth generation and using education to empower the citizenry (NERDC, 2007).

The then existing primary and junior secondary school curricula were restructured into a 9-year Basic Education Curriculum (BEC). BEC included new subject matter in Science, technology, mathematics, national values, cultural and creative arts, information communication technology (ICT) as well as foundations in vocational studies and entrepreneurship among others (Obioma, 2012).Regular reviews and restructuring of the curriculum took place to ensure relevance to dynamic human society and culture and to respond to global reform and the need to attain the Millennium Development Goals (MDGS) by 
2015.According to FME (2007: iv) the 9-year basic education curriculum is sub-divided into three parts:

* Lower basic education comprising, classes 1-3

* Middle basic education comprising, classes 4-6

* Upper basic education classes 7-9 (that is JSS I -3)

\section{Cultural and Creative Arts}

Cultural and creative arts education is an amalgamation of fine and applied art, music and drama. It is an umbrella term which brings together the three arts subject areas; music, fine and applied arts and drama/theatre. The infusion of knowledge, skills, attitudes and values in the several components of CCA enhance entrepreneurial skill acquisition which begets good theatrical performance and good art work. The outcome of these art products is believed will make the learner achieve self fulfilment and actualization (Buoro, 2000). The discipline has been introduced as a holistic and integrated subject that reflects the society and the environment as well as various aspects of people's culture; it employs cognitive processes ultimately allowing language and thought to be expressed through a variety of representations. This is represented not in the ordinary sense of language, as writing on a paper but in either a visual, kinesthetic, aural or tactile form (Alter, Hays \&Harra,2009). This is in agreement with what used to constitute the arts in traditional culture where music, dance, drama, et cetera are usually integrated and often are performed and presented together at appropriate occasions, in order to promote the cultural heritage of the people. Activities emanating from cultural and creative arts education should have relevance on the people's way of life and survival as individuals or groups. The CCA education is aimed at developing the students' acquisition of cultural repertoire, aesthetic perception, artistic talents, creativity and expression. It is 
also designed to stimulate interest and inquiry into the theoretical and practical areas of the arts in school. It has been listed as one of the core basic subjects for which specialist teachers should be provided by NERDC in the new 9-year basic education curriculum (Federal Republic of Nigeria, 2004). It is in this light that RussellBowie (2009) posits that arts can embody and communicate emotions, ideas, beliefs and values; they can convey meaning through aesthetic forms and symbols and evoke emotive responses to life with or without words.

\section{Brief History of Cultural and Creative Arts in Nigeria}

The integration of the three major arts subjects has been achieved in some countries of the Western world as arts education and had been in existence in different forms during the $19^{\text {th }}$ century. The ancient world held the arts education in high esteem and it was included in their curriculum. Arts education gained popularity as part of John Dewey's 'Progressive Education Theory.The Nigerian government equally recognized that arts education is the expression of the people since it reflects the society, the environment and aspect of their culture. These therefore constitute the underlying principles for formulating the philosophy of cultural and creative arts education for primary/junior secondary school in Nigeria.

CCA curriculum was first proposed in Nigeria in the Lagos curriculum conference of 1969 to be one of the six core curricula used in the primary school (Olaosebikan, 1982). It was stated in the conference that one of the aims of CCA is to impact in learners, cultural and practical values of the society to which they belong. The policy makers believe that engaging children in the creative arts can allow them communicate in potentially profound ways (Eisner, 2002). According to Olaosebikan, CCA is like a catalyst 
that speeds up and controls the process of cultural diffusion in a most meaningful way that will give a Nigerian child a sense of direction and sound judgment to re-enact the Nigerian cultural heritage. The subject is also aimed at expressing the emotions, experiences, ideas and feelings beyond the reach of language. Hence the subject was very much recognized and rated by Wangboje (1982) as the foundation program that would serve the needs of students in developing their creative imaginations, self realization, self actualization as well as sharpening intelligence and creativity.

Consequently, in 1971, the Nigerian Education Research and Development Council (NERDC) organized a workshop where specialists in drama, education, music, fine and applied arts met to spell out what the programme should cover for the secondary school education level. As a result of the conference, CCA program was adopted for secondary education but due to logistic problems such as lack of instructional resources and qualified teachers, the program couldn't take off until the introduction of the 9-year Universal Basic Education (UBE) in 2007 (NERDC, 2008). The curriculum stated that CCA should be made a core and compulsory subject at the UBE levels which consists of Lower Basic education (Primary 1-3), Middle Basic (Primary 4-6) and Upper Basic Junior Secondary School (JSS1-JSS3). The learning activities embedded in this curriculum were exciting, interesting and filled with useful knowledge and skills, which are capable of building confidence in the recipients when strategically packaged.

In developing the programme, NERDC in 1973 developed the aims and objectives of CCA in primary schools in Nigeria to include:

- Development of the language of expression of ideas, feelings, emotions and moods through different ways of experience. 
- Developing interest for a future vocation in the arts and seeing the values of the art in other school subjects.

- Having adequate skills and competencies for higher education in the arts and creating an environment that will involve the students in sharpening their aesthetic experience in the cultural pattern.

- Understanding the various uses of art materials as mediums of expression and helping pupils to develop the techniques of artistic production and appreciation through performance evaluation (NERDC, 2008).

The objective of primary school CCA became a spring board for the take off of CCA programme at the junior secondary school (JSS) under the 9-year basic education curriculum in 2007. The new arrangement grouped CCA, agricultural science, business studies and home economics as vocational subjects (NERDC, 2008). Under the new programme, the objectives of the vocational subjects at the JSS include:

- Encouraging partnership among Nigerians in promoting our rich cultural heritage and creativity.

- Infusing certain emerging issues as gender, sensitivity, world globalization, health issues, etc into the curriculum.

- Re-orientating Nigerians to have positive values for the enhancement and development of the Nigerian society.

- Equipping young Nigerians with manipulative skills which will make them job creators and self reliant entrepreneurs.

These components of CCA are integrated into a composite structure called Broad Field Curriculum (BFC). The design is the outcome of a few courses that combined specific areas of related subjects into large fields to eliminate the single subject 
compartmentalization and atomization of learning (Offorma, 2002). BFC has the following characteristics:

- It takes care of the interest of the learner.

- It facilitates more functional organization of learning because the learner can draw experiences from the wider subject area to solve contemporary problems.

- The organization permits broader coverage and allows the elimination of excess factual details.

- It cuts across subject boundaries and therefore provides comprehensive knowledge for the learner. The comprehensive knowledge provides sound entry behaviour for further study in the affected subject area. Example: CCA activities in the JSS should provide a good experience for learners in SSS.

All the above mentioned structuring and restructuring of the programme notwithstanding, the importance of teaching CCA in schools still appears to have often been viewed as seemingly less essential than other core subjects particularly by school administrators and even the society. This may have been the reason why several previously held workshops focused predominantly on subjects such as English language, mathematics, basic science, basic technology and social studies. This study investigated the views of CCA teachers who have been in the process to find out the extent the restructuring and other emerging issues affect the teaching and learning of CCA in schools.

\section{Methodology}

An oral interview was conducted within the selected five upper basic schools in Awka educational zone in Anambra State in order to find out the extent the CCA teachers have embraced the compound-subject as well as their reflections upon their 
own arts pedagogy and other emerging issues. A total of eight (8) teachers were interviewed in their respective schools at appointed dates and a total of sixteen questions were postulated. Awka educational zone is comprised of five (5) Local Government Areas. In each of the local government area, one school was selected through random sampling technique. In all, five (5) schools were selected and all the CCA teachers in the five schools were interviewed. The schools are as follows:

Table 1: Showing the selected schools and the number of the CCA teachers.

\begin{tabular}{|c|c|c|c|}
\hline $\mathbf{S} / \mathbf{N}$ & $\begin{array}{c}\text { Local } \\
\text { Government } \\
\text { Area }\end{array}$ & Name of School & $\begin{array}{c}\text { Number of } \\
\text { CCA } \\
\text { Teachers }\end{array}$ \\
\hline 1. & Anaocha & $\begin{array}{l}\text { Girls' High } \\
\text { School, Agulu }\end{array}$ & 2 \\
\hline 2. & Awka North & $\begin{array}{l}\text { Community } \\
\text { Secondary } \\
\text { school, } \\
\text { Amansea }\end{array}$ & 1 \\
\hline 3. & Awka South & $\begin{array}{l}\text { Igwebuike } \\
\text { Grammar } \\
\text { School, Awka }\end{array}$ & 2 \\
\hline 4. & Dunukofia & $\begin{array}{l}\text { Girls' } \\
\text { Secondary } \\
\text { School, } \\
\text { Umudioka }\end{array}$ & 1 \\
\hline 5. & Njikoka & $\begin{array}{l}\text { Boys Secondary } \\
\text { School, Enugu- } \\
\text { Ukwu }\end{array}$ & 2 \\
\hline Total & 5 & 5 & 8 \\
\hline
\end{tabular}


Out of the five schools visited, two were all boys' schools; two were all girls' schools while one school was a mixed school. It is worthy of note that out of the eight CCA teachers interviewed, seven of them were female while only one was male. This goes to show that males are fast disappearing from the teaching of CCA in the basic school.

The following questions were postulated for the oral interview (not including the preliminary personal data and other probing questions that arose from the responses of the respondents).

- What is the level of students' enthusiasm in response to CCA learning after the revised curriculum?

- Did the revision of the curriculum enhance students' achievement in the subject?

- Has the new curriculum enhanced the chances of more students choosing music in the senior secondary school?

- Did the merging of other basic education subject areas make CCA more acceptable to its teachers and students?

- How many new CCA specialist teachers have been posted to your school since after the revision of CCA?

- How many workshops and seminars have been held for CCA teachers since the revision of the curriculum in other to ensure that CCA teachers adapt to the revised curriculum?

- How do you cope, teaching other subject areas of CCA that are not your area of specialty?

- How do you handle other CCA areas outside your specialty area that require practical examples?

- How many non-music specialists can play any Western instrument to a reasonable standard? 
- How adequate is the time allotted to CCA in the school time table?

- Is there any specification of time in the school time table for practical in CCA?

- Do you have at your disposal enough CCA textbooks that are rich in content to cover all the themes in the CCA curriculum?

- How balanced are the authors of CCA textbooks in terms of specialty areas?

- What are the efforts made by the curriculum planners to harmonize the themes of the three art areas in the revised curriculum?

- How often do government and school authority provide instructional material for the teaching of CCA since the revision?

- What efforts have the school authority and the government made to enlighten the parents about the benefits of CCA for their wards?

\section{Results of the Findings}

Having interviewed the eight CCA teachers derived from the five schools that served as the sample of the population, the responses were analyzed and the outcome was quite revealing.

All the CCA teachers interviewed revealed that several reviews of the curriculum have taken place all geared towards making the CCA curriculum better and acceptable for both the teachers and the students but the issue lies in the readiness of the government and the curriculum planners to make serious move towards improving on the already existing standard. One hundred percent of the respondents agreed that due to the series of complaints from various interest groups, the government has 
tried to a large extent to harmonize the themes of the three art areas of CCA. Ninety-eight percent of the respondents were of the opinion that several revisions in the CCA curriculum to a high extent settled the problem of imbalance in the curriculum thereby soothing the teachers' feelings of marginalization of their specialty area. Only two percent insisted that there is still imbalance in the curriculum. Ninety-five of the respondents feel that the merging of other subjects in the basic schools actually made the teachers of CCA more relaxed, knowing that they are not alone and that their subject is not in any way inferior to others.

On the issue of posting new CCA specialists to teach in the basic schools, all the teachers interviewed averred that no new CCA specialist teacher had been posted except that the active teachers in the field are being reshuffled/transferred from one school to another. All the teachers interviewed agreed that few workshops and seminars have been held but none of the workshops/seminars was aimed at helping the teachers to overcome the challenges of CCA but to remind the teachers the need for them to embrace CCA and devise ways of overcoming these challenges by seeking help from one another and studying the existing CCA textbooks.

On how the teachers cope with the teaching of other areas of CCA outside their specialty, Seventy percent of the respondents who are non-music specialists averred that the music aspect of the curriculum suffer most because they find it difficult to understand even after they have studied the textbook. Thirty percent who happened to be music specialists opined that they read and teach other areas to satisfaction though, with little difficulty but derive greater joy in teaching music aspect. This makes one wonder what happens to the 
practical aspect of the subject. Ninety-eight percent of the teachers agreed that the practical aspect of the subject is not taken care of except when it is in one's area of specialization. Eighty-five percent of the respondents posit that students show high level of enthusiasm when a specialist in a particular area is handling that aspect of CCA as opposed to when it is handled by a non specialist.

Ninety-four percent of the respondents are of the opinion that it was only one out of all the authorized CCA textbooks were balanced in terms of curriculum coverage and authors' specialty. Only six percent said that they consult several textbooks while planning a single lesson. In the area of providing instructional materials, ninety percent of the respondents highlighted that the government and the school authority are not forth coming. They pointed out that provision of instructional materials is left for class teachers making most teachers deliver their lessons without instructional materials. Ninety-four percent of the respondents posit that time allocation in the time table still remain the same with no time allotted to CCA practical, the reforms in the curriculum notwithstanding. Only six percent of them said a period of forty minutes was added to CCA in their school; in that case, the teacher believed that the added time was because the school principal is a specialist in one of the art areas of CCA. On the issue of non-music specialists playing Western instruments, ninety-eight percent were unable to do this while only one teacher agreed to playing drums and a recorder to an appreciable extent as a result of being in charge of a church band.

One hundred percent of the teachers attested that both the school and the government made no effort to enlighten the 
parents about CCA because they see it as none of their business since the merger and the reforms came from the federal government of Nigeria and the curriculum planners.

\section{Discussion of the Findings}

The present upper basic school curriculum of which the CCA curriculum is inclusive is geared towards not only theoretical concepts but also application of appropriate skills required in the development of arts, science and technology for the survival of individuals in our society. The policy on the implementation of the curriculum directs that the government will take measures to see that the culture of the nation be kept alive through arts, music and other cultural studies in schools, local governments, states and through national festivals of arts. The curriculum of cultural and creative arts is primarily concerned with the role arts and culture play in the education of the present and future generations. There is no gainsaying that quality art education can produce positive learning outcomes, such as creating positive attitude to learning, developing a greater sense of personal and cultural identity and fostering more creative and imaginative ways of thinking in young people (Bamford, 2006; Eisner,2002; Robinson,2001).

The positive findings from this study revealed that the merging of the arts subjects into one single subject offers all the students, opportunity to acquire musical knowledge since music has become a compulsory subject; quite unlike before, when students had to choose between music and other subjects. Secondly, as can be witnessed from the teachers' responses, there is a general consensus that several reforms have taken place in the basic education curriculum of which CCA is one. It is good news that the government has made frantic efforts to 
reform the curriculum of CCA; at least it shows that the government listened to calls from various stakeholders of CCA. It is in that light that Obioma (2012) posits:

Curriculum reforms have given rise to reforms in assessments. As school curricula are being reformed in Nigeria, there is need for school teachers to be equipped with assessment skills that will bring about effective delivery of the new curriculum subject matter. This should also be lessons gained for developing communities especially African countries currently engaged in school curriculum reforms (P. 5).

Apart from the above positive observations, the findings reechoed the traditional economic problems of music in schools which bordered on perennial problems of personnel, materials, management and finance. The point still lies that the teachers who will execute this task are yet to be reformed after all these years as can be seen from the teachers' response concerning workshops and seminars on CCA and posting of specialists CCA teachers to schools. One of the top priorities identified in any country is the training of their teachers. Adenipekun (2005) remarks: "the development of human capital is the most important duty of any progressive country. Man is the centre of development and the teacher is the key" (p.31). There is still need to provide both inservice courses and seminars to update teachers' skill in the use of new curriculum and opportunities for teachers to replenish their own creativity. This has far reaching effects as Ugoo-Okonkwo (2015) observes:

Managerial deficiencies, haphazard and uncoordinated approaches in tackling the problems and challenges of CCA could have been streamlined and harmonized if music 
teachers are invited for workshops and seminars; unfortunately, this was not the case, and they use any method within their disposal at least to get going (p. 48 ).

It should be noted that teachers' preparedness and value for CCA are highly relevant in regards to students' artistic learning and development but dearth of research that explores what ought to be the best practice in CCA teaching and learning in Nigeria is lacking. The findings from this study confirms the claims of a number of other similar studies in Nigeria that there is undeniable gap that exists between the expectations of our curriculum framework and preparation in the art areas that can be provided by initial teacher education courses. This study shows that CCA teachers' lack of quality arts education and the time devoted to teaching in these key art areas in Nigerian basic schools did not adequately prepare teachers for their responsibilities. Teachers felt overwhelmed by the demands of the content, knowledge and skills required to teach in all the creative art subjects especially music aspect. Many considered that it was impossible to be skilled and competent in teaching all the facets of CCA. Some of the participants of this study described how they sought out expert help from others when they felt that their skills and knowledge were insufficient to the task of teaching any of the arts strands.

This study also discovered that teachers are lacking in schools. Think of a situation where one teacher is meant to teach over three hundred students. It becomes almost impossible for the teacher to put in his/her best. The government's reluctance to employ qualified art and music teachers is seriously hampering the progress of the CCA programme in schools. Irivwieri (2009) poignantly asserts: 
There is at present a dearth of qualified art and music teachers in secondary schools. Most of the schools lack the professionally trained graduate art and music teachers, who are much more exposed both academically and professionally to handle the programme well at the secondary school level (p. 351).

Apart from the issue of shortage of qualified teachers, the study also found out that instructional materials are not provided for the teaching of CCA. Both the government and the curriculum planners are not doing enough to provide the teaching aids required for effective teaching of CCA. Irivwieri (2009) notes, "with the non-availability of these basic equipment, tools and materials, the Creative Arts curriculum is adversely affected" (p.351). Still on the indispensability of instructional materials and musical instruments to the teacher, Ezeani (1999) poignantly posits, "the use of instructional materials make teachers' work simpler because by serving as illustrations for certain abstract concepts, they make teachers' lesson more understandable, nearer home and so more meaningful" (p. 160). It is in that light that Irivwieri further remarks:

Most of the schools lack equipment, teaching aids and materials. Musical instruments such as piano, xylophone and basic equipment such as gramophone records, tape recorder, cassette and video tapes are not provided in Music Departments in these Secondary Schools. With the nonavailability of this basic equipment, tools and materials, the Creative Arts curriculum is adversely affected (p.351).

The study further found out that beyond the issue of lacking musical instruments, in some places where these musical instruments are available, CCA teachers' (especially non-music 
specialists) inability to use the available musical instruments constitutes a big problem and thus the music aspect of the CCA suffers a great deal. It was also observed that despite the reforms, practical periods for CCA on the timetable are still unspecified. Ekwueme (2009) cautions that "CCA as a subject is practical or skill oriented. There should be time allocated for practical, but unfortunately no time is allocated for music practical" (p. 41). Students gasp more when they are practically involved in the teaching and learning situation.

\section{Recommendations}

To address the emerging issues in CCA curriculum now the school curriculum is undergoing reforms, there is need for similar reforms in pedagogical contexts at the pre-service teacher education level especially as they affect assessment practices for both the teachers and the students. There should be capacity building workshops designed for serving teachers. Provisions should be made for CCA specialists to be employed in various schools to encourage team teaching in order to achieve set goals. This is very important if the CCA set out goals are to be met. The implementation demands the attention of a creative and a very resourceful teacher capable of appreciating the benefits of the curriculum from one stage to the other.

There is urgent need for the government to organize workshops, seminars and symposiums. The government should start to perceive teachers as the key figures in delivering a relevant, creative and enjoyable experience of arts and education. Teachers cannot attain their full potential without adequate support in terms of professional development, curriculum guidance and access to resources within and outside the school. 


\title{
Conclusion
}

The study discussed the emerging issues in the 9-Year basic education curriculum in Nigeria as it concerns the teaching and learning of cultural and creative arts education from the perspective of the teachers. It established that several restructuring attempts to improve the programme have taken place but the implementation has been hampered by a lot of problems. The policy was not matched with the provision of adequate manpower, funds and infrastructural facilities. The cultural and creative art education of a child should be such that will make him see knowledge as a totality, embodiment of life and a way of life rather than a living. Creative impulses do not exist in a vacuum. They are only meaningful in the context of a society and present in all human beings. But for one to excel in art, this creative instinct has to be cultivated, nourished and exercised so that it can be stimulated in others.

In conclusion, the series of reforms so far obviously have not radically influenced the cultural and creative art education in Nigeria. It however became a reference point to the discussion of education policy and to certain initiatives and gave a renewed sense of priority for developing basic education.

\author{
Ebele V. Ojukwu \\ Department of Music \\ Nnamdi Azikiwe University, \\ Awka \\ ev.ojukwu@unizik.edu.ng
}




\section{References}

Adenipekun, O. (2005) Fafunwa Seeks Reward for Teachers. Vanguard Educational Weekly, p. 31.

Alter, F. A., Hays, T. N. \& Harra, R. O. (2009) The challenges of implementing primary arts education: What our teachers say. Australasian Journal of Early Childhood, 3, 4, 20 30 .

Bamford, A. (2006) The Wow Factor: Global Research Compendium on the Impact of Arts in Education. New York: Waxmann Munster.

Buoro, E. A. (2000) Art in the service of technology. Journal of Art Education Proceedings of Africa and the middle East Regional Congress of INSEA, 27, 1, 83-87.

Eisner, E. (2002) The Arts and the Creation of the Mind. New Haven: Yale University Press.

Ekwueme, L. U. (2009) Competency-based teacher education in music/cultural and creative arts: A suggested approach for the universal basic education (UBE) programme. Interlink: A Journal of Research in Music, 4, 33-47.

Ezeani, L. U. (1999) Improving the teaching-learning process. In B. U. Maduewesi, L. U. Ezeani \& C. P. Maduewesi (Eds.), Curriculum Implementation and Instruction (pp.155-166). Onitsha: West and Solomon Press.

Federal Ministry of Education, (2007) 9-year Basic Education Curriculum, Cultural and Creative Arts for Junior Secondary 1-3. Abuja: Nigerian Educational Research and Development Council Press.

Federal Republic of Nigeria, (2004)National Policy on Education (4th ed.). Lagos: Nigerian Educational Research and Development Council Press. 
Irivwieri, G. O. (2009) The implementation of the creative arts curriculum in secondary schools in Nigeria. African Research Review: An International Multi-Disciplinary Journal, 3, 3, 342-358.

Nigerian Educational Research and Development Council (NERDC), (2007) New Senior Secondary Education Curriculum, Lagos: NERDC Press.

Nigerian Educational Research and Development Council (NERDC), (2008) Teachers Handbook for the 9-year Basic Education Curriculum (Junior Secondary Level). Lagos: Nigerian Educational Research and Development Council Press.

Nwachukwu, O. P. (2012) Understanding the New Revised Basic Education Curriculum. Awka: Nigerian Educational Research and Development Council Press.

Obioma, G. (2012)Reforms in the Nigerian 9-year Basic Education Curriculum: Implications for School-based Assessment. Paper presented at the $38^{\text {th }}$ Annual Conference of the International Association of Educational Assessment, Radisson Hotel Astana City, Kazakhstan, 16-21 September.

Offorma, G. C. (2002) Curriculum Theory and Planning. Enugu: Family Circle Publication.

Ojukwu, E. V. (2011) Dysfunctional Music Education in the Junior Secondary Schools in Anambra State, Nigeria. Unpublished Doctoral Dissertation, Department of Music, NnamdiAzikiwe University, Awka.

Olaosebikan, W. A. (1982) Cultural and Creative Arts: A Resource Book for Teachers. Ibadan: Evans Brothers.

Robinson, K. (2001) Out of Our Minds: Learning to be Creative. West Sussex: Capstone Publishing 
Russell-Bowie, D. (2009) MMADD About The Arts: An Introduction to Primary Arts Education. Frenchs Forest, NSW: Person Education Australia.

Ugoo-Okonkwo I. A. (2015) Teachers' perception on the functionality of the introduced cultural and creative arts curriculum of the Nigerian universal basic education. Journal of Elementary Education, 24, 2, 33-50.

Wangboje, S. I. (1982) A textbook on Art for Senior Secondary Schools. Ibadan: Evans Brothers. 